\title{
VER E OUVIR EM UM ESPAÇO DE MEMÓRIA
}

\section{See and hear in a memory space}

\section{Ver y oir en un espacio de memoria}

\author{
José Venceslau Pereira Duque ${ }^{1}$ https://orcid.org/0000-0003-3503-8095 \\ Reuel Machado Leite ${ }^{2}$ https://orcid.org/0000-0002-8426-9036
}

Andrecksa Viana Oliveira Sampaio ${ }^{3}$ https://orcid.org/0000-0002-7826-0908

\footnotetext{
${ }^{1}$ Aluno Especial do Programa de Pós Graduação em Geografia (PPGEO/UFS) venceslau.duque@ hotmail.com

${ }^{2}$ Doutorando em Geografia do Programa de Pós Graduação em Geografia (PPGEO/UFS) reuelmachadoleite@gmail.com

${ }^{3}$ Pós Doutoranda em Geografia pelo Programa de Pós Graduação em Geografia (PPGEO/UFS). Doutora em Geografia pela Universidade Federal de Sergipe (UFS). andrecksa.oliveira@uesb.edu.br
}

Recebido em: 20/03/2019

Aceito para publicação em: 11/05/2019

\section{Resumo}

O presente estudo teve como objetivo retratar o significado de lugar através da observância e interação entre os frequentadores do terreiro Oxogunladê, na cidade de São Cristóvão, Sergipe, Brasil. O lugar é o redimensionamento do espaço dotado de sensações, afeição e referências de experiência vivida. Está relacionado com a prática cotidiana, do vivido, do desenvolvimento da vida em todas as suas dimensões. As histórias contadas no passar do tempo estão impregnadas no meio, através de relatos de saudade, além de registros e sinais de ausência. $\mathrm{O}$ auto reconhecimento só acontece quando o indivíduo conhece a própria história, o caminho percorrido, em que o sentimento de pertença, afetividade e identidade se afloram através da integração temporal.

Palavras-chave: Espaço. Lugar. Memória.

\begin{abstract}
The present study had as objective to portray the meaning of place through the observance and interaction between the goers the Oxogunladê yard in the city of Saint Cristopher, Sergipe, Brazil. The place is the resizing of the space endowed with sensations, affection and references of lived experience. It is related to the daily practice, the lived, and the development of life in all its dimensions. The stories told in the course of time are impregnated in the middle, through reports of missing, as well as records and signs of absence. Self-recognition happens only when the individual knows own history, the path traveled, in which the feeling of belonging, affectivity and identity surface through temporal integration.
\end{abstract}

Keywords: Space. Place. Memory. 


\section{Resumen}

El presente estudio tuvo como objetivo retratar el significado de lugar a través de la observancia e interacción entre los frecuentadores y responsables del terreiro Oxogunladê, en la ciudad de San Cristóbal, Sergipe, Brasil. El lugar es el redimensionamiento del espacio dotado de sensaciones, afecto y referencias de experiencia vivida. Está relacionado con la práctica cotidiana, de lo vivido, del desarrollo de la vida en todas sus dimensiones. Las historias contadas en el paso del tiempo están impregnadas en el medio, a través de relatos de nostal, además de registros y señales de ausencia. El auto reconocimiento sólo ocurre cuando el individuo conoce la propia historia, el camino recorrido, en el que el sentimiento de pertenencia, afectividad e identidad se afloran a través de la integración temporal.

Palabras clave: Espacio. Lugar. Memoria.

\section{Introdução}

Neste artigo objetivamos abordar a categoria geográfica lugar, entendendo-a enquanto inerente ao espaço social e sua multidimensionalidade. Em específico, abordamos o lugar de memória, tomando como parâmetro a interação com uma comunidade de terreiro chamado Ilê Axé Opô Oxogunladê. Para tal, além de revisão bibliográfica sobre o tema, realizamos trabalho de campo no ano de 2018, e nesta ocasião entrevistamos o líder religioso Reginaldo Daniel Flores, se utilizando de questionário não estruturado.

A categoria lugar de memória lança luzes sobre uma comunidade de terreiro quando entendemos a importância dos saberes herdados. A memória neste Ilê Axé, ela é a garantia para que os procedimentos, os comportamentos e hábitos, em suma, o uso do espaço obtenha um parâmetro para que a organização social do terreiro se reproduza. Segundo os sujeitos desta comunidade, na vivência do terreiro se aprende vendo e ouvindo, o uso da linguagem textual, portanto, não é um instrumento chave para se manter viva a prática e a memória do terreiro. Para nos dar suporte a leitura destas questões, iremos ao debate da categória espaço.

\section{Espaço e multidimensionalidade}

O espaço, entendido enquanto social é aquele que contém os lugares apropriados às relações sociais de produção, compreendendo, portanto, as biofísiológicas (como por exemplo, a reprodução da família) e as de produção, englobando a divisão social do trabalho, sua organização e as funções sociais hierarquizadas (LEFEBVRE, 2000).

A noção de espaço social denota uma perspectiva geral das suas características, afinal este é o habitat da sociedade, da produção e reprodução da vida, por meio da relação dialética entre seres humanos e natureza e entre os próprios seres humanos (LEFEBVRE, 2000). A 
produção do espaço social envolve, também, a criação de diferentes formas e características deste que, não obstante, interagem dialeticamente.

Lefebvre (2000) elabora uma tríade conceitual com a finalidade de apreender estes diferentes espaços, são eles: o percebido, que aquele da realidade cotidiana, da experiência e da percepção aberto ao toque físico à sensação, que sugere, portanto, uma prática espacial; o concebido ou as representações do espaço, aquele dos cientistas, dos planificadores, dos urbanistas, dos tecnocratas "retalhadores" e dos cartógrafos, ou seja, mapas, plantas, croquis; o vivido ou os espaços da representação, ou seja, o espaço vivido através das imagens e símbolos que o acompanham, portanto, espaço dos "habitantes", dos "usuários", mas também de certos artistas e talvez dos que descrevem e acreditam somente descrever: os escritores, os filósofos.

Harvey (2012), inspirado nas ideias de Lefebvre (2000) formula também uma tríade conceitual, podendo o espaço ser: absoluto, relativo ou relacional. Aqui é importante salientar, que estas três diferentes características não podem ser entendidas separadamente, mas em constante interação e tensão dialética entre si.

O espaço absoluto, de acordo com os argumentos de Harvey (2012, p. 10), é o espaço de Newton e Descartes, usualmente representado como uma grade pré-existente e imóvel, ou seja, é o campo do material sensível, do fixo, é o espaço da geometria, da propriedade privada e de outras entidades territoriais delimitadas. Então, desde os objetos em sua dimensão física sensível, às dimensões geométricas de uma casa ou uma praça, as fronteiras territoriais de um país, compreendem, portanto, o espaço absoluto.

Para formular o conceito de espaço relativo, Harvey (2012) toma emprestado as ideias de Einstein que dizem que todas as formas de medição dependem do modelo de referência do observador. Este espaço só pode ser entendido em sua relação com o tempo, ou seja, busca a compreensão de um espaço-temporalidade, sendo por isto, ainda de acordo com os argumentos de Harvey (2012), possível criar diferentes mapas de localização entre distâncias medidas em termos de custo, tempo, modo de transporte, entre outros.

Sobre à visão relacional do espaço, o outor supracitado sustenta que não há espaço ou tempo fora dos processos que os definem. "Processos não ocorrem no espaço mas definem seu próprio quadro espacial. O conceito de espaço está embutido ou é interno ao processo" (HARVEY, 2012, p. 12). O espaço aqui é compreendido em suas relações, ou seja, um ponto no espaço não pode ser entendido isoladamente ou com relação ao que existe somente naquele ponto, como exemplo tem-se as relações sociais de produção, as leis, os espaços mentais subjetivos, os conflitos políticos, dentre outros. 


\section{O lugar...}

Do conceito de espaço relacional, percebido e vivido emerge a ideia de lugar. Espaço do vivido, da relação direta com o espaço, do olhar, da relação de vizinhança e proximidade. O lugar é o espaço do contato por excelência, do comum, palco de realização da vida, como assim ressalta Carlos (2015):

Nessa direção, abre-se como perspectiva analítica o desvendamento da realidade em constituição, iluminando o plano da análise da vida cotidiana enquanto lugar da reprodução contraditória da vida. Isso significa dizer que o processo de produção do espaço, nessa perspectiva, não se reduz à produção material do mundo (CARLOS, 2015, p. 28).

Ainda segundo a mesma autora, qualquer que seja a organização global dos usos ou o modo de produção do espaço, uma racionalidade que se tornou cada vez mais necessária parece reinar sobre o lugar, em que a produção do construído privilegia uma certa manipulação do espaço sob uma lógica repetitiva e fundamentada em produzir inicialmente um habitat, depois liberá-lo para uso, e acrescenta:

Nessa orientação, a produção social do espaço permite desvendar o sentido do termo apropriação a partir do habitar como prática sócio-espacial que ganha objetividade no lugar, nos atos e ações da vida cotidiana, como local onde se estabelece o vínculo com o outro. Nesse sentido, a produção do espaço da vida humana comportaria um movimento incessante proveniente do ato/ação continuados da reprodução social (CARLOS, 2015, p. 38)

Moreira e Hespanhol (2007, p. 51) retrata que no lugar o "habitar implica mais do que simplesmente morar ou organizar o espaço, significa viver de um modo pelo qual se está adaptado aos ritmos da natureza", colocando-se em contato com o exterior e localizando o outro, comunicando-se com outros homens e conhecendo outras situações.

Do ponto de vista radical, o lugar é qualificado como construção sociohistórica que cumpre determinadas funções. Este, portanto, está atrelado a funcionalização do mundo, mas sobre outro ângulo, assim caracterizando-se como o espaço da comunicação, do cotidiano, da vizinhança, etc. Portanto, "cada lugar é, ao mesmo tempo, objeto de uma razão global e de uma razão local, convivendo dialeticamente (CABRAL, 2007, p.273)".

De acordo com Moreira e Hespanhol (2007), no passado, o lugar era associado à ideia de região e de localização geográfica, sendo até mesmo tratado com os mesmos significados de território e paisagem, contudo, salientam que compreender o lugar é considerá-lo não como uma soma de objetos, mas como um sistema de relações. E ainda:

O lugar se estrutura na relação do "eu" com o "outro", o palco da nossa história, em que se encontram as coisas, os outros e a nós mesmos. O corpo 
situa-se na transição do eu para o mundo, o ponto de vista do ser-do-mundo, sendo a condição necessária da existência humana (MOREIRA; HESPANHOL, 2007, p. 51).

A redefinição de lugar, para as Ciências Humanas e principalmente para a Geografia, passou a representar um problema diante do processo de globalização que hoje se realiza mais acelerado que em outros momentos da história (CARLOS, 2007). Entretanto, cabe salientar que existe um consenso em que a redefinição de lugar está relacionado com a realização da prática cotidiana, do vivido, do desenvolvimento da vida em todas as suas dimensões, assim caracterizado pela mesma autora como:

O lugar é a base da reprodução da vida e pode ser analisado pela tríade habitante - identidade - lugar. A cidade, por exemplo, produz-se e revela-se no plano da vida e do indivíduo. Este plano é aquele do local. As relações que os indivíduos mantêm com os espaços habitados se exprimem todos os dias nos modos do uso, nas condições mais banais, no secundário, no acidental. É o espaço passível de ser sentido, pensado, apropriado e vivido através do corpo (CARLOS, 2007, p. 17).

Segundo Moreira e Hespanhol (2007), a identidade, o sentimento de pertencimento e o acúmulo de tempos e histórias individuais constituem o lugar, em que este guarda em si o seu significado e as dimensões do movimento da história apreendido pela memória através dos sentidos. Ainda de acordo com as referidas autoras, o lugar contém multiplicidades de relações ao mesmo tempo em que pode ser compreendido enquanto uma realidade sensível, correspondendo ao uso e à prática vivida no cotidiano.

Nesse sentido, o lugar passa a ser considerado como responsável pela apropriação do espaço, executor das nossas ações, ou seja, aquilo que pode ser vivido através do uso, pelo corpo, um espaço palpável, onde é imprescindível a ocorrência de relações, como afirma Carlos (2007):

O lugar é produto das relações humanas, entre homem e natureza, tecido por relações sociais que se realizam no plano do vivido, o que garante a construção de uma rede de significados e sentidos que são tecidos pela história e cultura civilizadora produzindo a identidade. Aí o homem se reconhece porque é o lugar da vida. O sujeito pertence ao lugar como este a ele, pois a produção do lugar liga-se indissociavelmente a produção da vida (CARLOS, 2007, p. 22).

Para Carlos (2007), no lugar, constitui-se o espaço apropriável para viver, sendo necessário ser um espaço vivido, conhecido e reconhecido em toda a sua amplitude, onde o corpo seria então o autor da apropriação do espaço. 
Ainda no tocante a definição de lugar, Andrade (2008), tomando como base a literatura atribuída a Tuan (1983), menciona que este é marcado por três palavras-chave que constituem sua essência: percepção, experiência e valores, distinguindo espaço e lugar, onde espaço pode transformar-se em lugar na medida em que se atribui a ele valor e significado, e este não pode ser compreendido sem ser experenciado.

O lugar seria o mundo vivido, em que cada pessoa teria seu lugar natural, um ponto de referência, onde habitar seria mais do que simplesmente morar ou organizar o espaço, seria viver de um modo pelo qual se está adaptado aos ritmos da natureza. Moreira e Hespanhol (2007) destacam:

O lugar se estrutura na relação do "eu" com o "outro", o palco da nossa história, em que se encontram as coisas, os outros e a nós mesmos. O corpo situa-se na transição do eu para o mundo, o ponto de vista do ser-no-mundo, sendo a condição necessária da existência humana (MOREIRA e HESPANHOL, 2007, p. 51).

O lugar é o redimensionamento do espaço dotado de sensações, afeição e referências da experiência vivida (ANDRADE, 2008). O lugar guarda em si, não fora dele, o seu significado e as dimensões do movimento da vida em constituição enquanto movimento da vida, possível de ser apreendido pela memória, através do sentido e do corpo (CARLOS, 1996).

Nesse sentido, segundo Andrade (2008), as memórias são importantes registros vividos que partem das lembranças e eternizam lugares como referências e cenários para uma constante visita ao passado.

\section{Lugares de memória...}

A apropriação simbólica do espaço acumulada de sentimentos e pertinência, o particulariza e o transforma em lugar (ANDRADE, 2008). Lugar de memória são lugares, com efeito, nos três sentidos da palavra, material, simbólico e funcional (NORA, 1993).

Segundo Andrade (2008), a memória está estratificada no lugar, em que as histórias contadas no passar do tempo estão impregnadas no meio, sedimentadas na saudade e a procura de registros e sinais da ausência que descrevem a memória do lugar. Nora (1993), em sua obra intitulada "Entre a memória e história: A problemática dos lugares”, ressalta:

A memória se enraíza no concreto, no espaço, no gesto, na imagem do objeto, surgindo os lugares de memória que são verdadeiros patrimônios culturais, projetados simbolicamente e podem estar atrelados a um passado vivido que ainda marca presença e reforça os traços identitários do lugar (NORA, 1993, p. 09). 
Assim, Andrade (2008), compartilhando dos mesmos conceitos de Gastal (2002), é categórico em afirmar:

Os lugares de memória e as memórias do lugar se conjugam em busca de instrumentos de reforço da identidade e da singularidade local. A população se constitui a mais importante ferramenta já que é depositária de informações, registros êmicos e sentimentos afetivos, resultado de uma relação com base na topofilia (ANDRADE, 2008, p. 570).

Para Andrade (2008, p. 572), “conhecer sua própria história, seu caminho percorrido, é um exercício de auto reconhecimento, de integração temporal, aonde as imagens do passado projetadas são transportadas através do sentimento de pertença, afetividade e de identidade local".

Ainda segundo a autora, como elo de interpretação do passado, a memória é a voz e a imagem do acontecido, em que conceituadamente, como propriedade de conservar certas informações, remete em primeiro lugar a um conjunto de informações psíquicas, graças as quais o homem pode atualizar impressões ou informações passadas, ou que ele representa como passadas.

Para Carlos (2007), repensar a identidade do lugar cada vez mais dependente e construída no plano do mundial faz com que, hoje, a história do lugar passe cada vez mais pela história compartilhada que se produz além dos limites físicos do lugar, de sua situação específica. O lugar guarda em si e não fora dele, o significado e as dimensões do movimento da história, possível de ser apreendido pela memória, através dos sentidos.

Com recorrência a memória, com os pés fincados no presente e voltados para frente, as lembranças de lugares, pessoas, costumes, culturas e objetos são artigos de valor e devem ser guardados com cuidado, para que esse patrimônio valioso e invisível esteja sempre a se enraizar no concreto, no espaço, no lugar.

\section{O lugar Oxogunladê...}

O candomblé, então religião de origem africana e apropriada por diferentes povos de diversas nacionalidades de referido continente que vieram para o Brasil (VERGER, 2006) e que em terras brasileiras, usando o idioma da família linguística nígero-congolesa chamada de yorubá, fundou-se o templo religioso com o nome de Ilé Asé (Casa de Axé).

Assim, os então chamados Yorubanos ou Nagôs fundaram as nações de candomblé Ketu e Ijexá, que cultuam os chamados Orixás, seres sagrados que a eles pertencem certos domínios da natureza e são intermediários na relação do homem com Deus. 
Originárias de Ketu, Iyanassô Assiká e Iyalussô Danadana, auxiliadas por Babá Assiká, então antigas escravas libertas pertencentes à Irmandade de Nossa Senhora da Boa Morte da Igreja da Barroquinha, tiveram a iniciativa de criar um terreiro de Candomblé chamado İyá Omi Àsé Àirá Intilé numa casa situada na Ladeira do Berquo, hoje Rua Visconde de Itaparica, próxima à Igreja da Barroquinha.

Essas duas mulheres posteriormente foram para Ketu, região da República do Benim, na África, e umas das mais antigas capitais dos yorubás, acompanhadas de Marcelina da Silva (Obatossí), onde passaram sete anos no referido continente.

Após referido período, Iyanassô e Obatossí voltam ao Brasil e com o auxílio de Rodolfo Martins de Andrade (Essa Onitikô), fundam em 1890 o Ilê Axé Iyá Nassô Oká (em yorubá), então Terreiro da Casa Branca (em português), na Avenida Vasco da Gama, em Salvador, Bahia, local este que ainda hoje se encontra sendo familiarmente chamado de Terreiro da Casa Branca do Engenho Velho e no qual Marcelina Obatossí tornou-se a mãe-desanto após a morte de Iyanassô.

Passados 30 anos após a fundação do Ilê Axé Iyá Nassô Oká ocorrido em 1890, Eugenia Ana dos Santos funda o Ilê Axé Opô Afonjá, casa de candomblé descendente da Nação Ketu, filho da Irmandade da Barroquinha, hoje situado em São Gonçalo do Retiro, um bairro da periferia de Salvador, Bahia. Sobre isso Pierre Verger (2009) esclarece essas raízes:

Eugênia Ana Santos, Aninha Obabii, cujo Orixá era Xangô, auxiliada por Joaquim Vieira da Silva, Obasanya, fundaram outro terreiro saído do Ilê Iyá Nassô e chamado Centro Cruz Santa do Axé [...]. Maria da Purificação Lopes, Tia Badá Olufandei, sucedeu, em 1938, a Aninha e deixou, em 1941, o encargo do terreiro a Maria Bibiana do Espírito Santo, Mãe Senhora Oxum Miua, filha espiritual de Aninha Obabii [...]. Senhora, abolindo o tempo passado graças a essa distinção, tornou-se espiritualmente a fundadora dessa família de terreiros de candomblé da nação Ketu, na Bahia, todos originários da Barroquinha. Confirmou tão elevada posição, em 1962, quando foi presidir, seguida de seus ogãs, o Axexê, ou cerimônia mortuária, da saudade e mais que centenária mãe-de-santo do Ilê Iyá Nassô da Casa Branca do Engenho Velho, Maximiana Maria da Conceição, Tia Massi Oinfunké [...]. (VERGER, 2009, p. 16).

Após a morte de Mãe Senhora, fundadora do Centro Cruz Santa do Axé, ocorrida em 1967, outras mães de santo a sucederam a liderança do Opô Afonjá, sendo que esta se encontra atualmente em vacância, após o falecimento de Maria Estella de Azevedo Santos, Ode Kayodê ou simplesmente Mãe Estella de Oxossi.

É do útero espiritual de Mãe Estella de Oxossi que o professor, intelectual e dançarino Reginaldo Daniel Flores, com nome sacerdotal de Ogún Toorikpé irá nascer na iniciação ao candomblé. 
Nascido na Ilha de Itaparica, no Estado da Bahia, filho de Clarice Daniel de Castro (Osun Toki), oriundo de família que historicamente vem mantendo a tradição de Baba Egun, culto aos ancestrais, que preza pela memória coletiva das tradições yorubanas no Brasil, fundadores do Ilê Tuntun na referida ilha.

Advindo do ventre espiritual e físico de mulheres de Oxum, Reginaldo Daniel sempre esteve e nunca saiu do ambiente sacerdotal, o seu lugar se molda por essa sociabilidade:

Durante sua infância e adolescência teve o privilégio de conviver com Mãe Senhora, Osun Muiwá (in memoriam et corde), renomada sacerdotisa do Afonjá, terceira responsável pela condução daquele terreiro. Com ela, Reginaldo aprendeu os primeiros segredos da vida sacerdotal. Ela o considerava como um filho que lhe acompanhava a todos os lugares e que velava seu sono, pois, muitas vezes, Reginaldo dormiu aos pés da cama de Mãe Senhora, sempre pronto a atendê-la (GOMES, 2015, p. 64).

Foi por meio dessa história que este filho da família Daniel de Paula se tornou Babalaxé (Pai do Axé) e fundou em 29 de julho de 2000 o Ilé Asé Opo Osogunladê, terreiro localizado na zona rural da cidade de São Cristóvão (1590), no Estado de Sergipe, distante 23 km da capital sergipana, Aracaju. São Cristóvão foi promovida à categoria de cidade histórica desde 1938, tombada pelo Instituto do Patrimônio Histórico e Artístico Nacional - IPHAN desde 1967, e desde 2010, teve a Praça São Francisco, também em referida cidade, tornandose patrimônio histórico da humanidade pela Organização das Nações Unidas para a Educação, a Ciência e a Cultura - UNESCO (GOMES, 2015).

A fundação deste terreiro se engendrou mediante a consubstanciação de energias e sociabilidades, tradições e histórias. A orientação de duas mães de santo de larga experiência e relevância no contexto do candomblé de Ketu como Mãe Estella e Mãe Nidinha de Iemanjá (neta de Mãe Senhora), ofereceram seu saber fazer sacerdotal.

Neste contexto, Deoscóredes Maximiniano dos Santos ou simplesmente Mestre Didi, artista plástico, escritor, ativista, sacerdote do culto a Baba Egun e Asogbá (sumo sacerdote da casa de Obaluayê) do Ilé Asé Opô Afonjá, também contribuiu para constituição dos fundamentos religiosos do terreiro.

Um quarto elemento, também importante foi o psicólogo, professor Doutor da Universidade Federal de Sergipe (UFS), Manoel Carlos C. de Mendonça Filho, que auxiliou financeiramente para compra do terreno, e trouxe alunos da referida Universidade onde leciona para conhecer o terreiro.

Em nossas entrevistas com o Babalaxé Toorikpé, ocorridas na residência do mesmo, frequentemente ele ressalta este traço da constituição do seu lugar que é a composição dos 
filhos e filhas da casa por alunos e ex-alunos da Universidade Federal de Sergipe. Os mesmos, ressalta o líder espiritual, trazem vícios acadêmicos atrelados a uma cultura livresca, que muitas vezes entram em choque com a prática sacerdotal do candomblé de Ketu, centrada em aprender fazendo e no uso do espaço como um lugar de memória.

Portanto, são nos gestos de mãos, nas reverências, frases, folhas, cânticos e temporalidade dentro do terreiro que o conhecimento sacerdotal e a sociabilidade no lugar irá se formar. Algo muito comum de ser ressaltado pelos filhos do terreiro é que "estamos em solo sagrado", isto quer dizer que todas as formas espaciais dentro do terreiro tem um significado, desde a chamada porteira até a fonte que se localiza no final do mesmo, salvaguardando a função de cada espaço e suas respectivas interdições ou não.

O espaço do terreiro é composto de elementos materiais: salão de Oxalá onde são feitas as reuniões públicas, casa dos orixás, onde são realizados rituis específicos para cada Orixá, o espaço mato (Foto 1), cozinha, porteira, fonte de água, casa do pai de santo, galinheiro e casa de ferramentas.

O egbé ou comunidade de terreiro possui uma organização própria, respeitando hierarquias e funções específicas, tendo por mais alta patente a figura do Babalaxé, em que o uso do espaço se engendra calcado na ideia de comunidade e uso coletivo do mesmo, ressaltando que existem espaços de uso comum e aqueles que só sacerdotes iniciados podem adentrar.

\section{Considerações finais}

O espaço socialmente produzido possui distintos momentos ou dimensões, que estão intrinsecamente relacionadas. Os lugares de memória como o Oxogunladê, expressam como os saberes e o sentido de ancestralidade podem definir um determinado uso do espaço, uma organização de uma comunidade de terreiro. O que é valorizado neste espaço são os livros vivos, os mais velhos guardiões das memórias de Mãe Aninha que remontam, por sua vez, os saberes herdados do Benin.

\section{Referências}

ANDRADE, Cyntia. Lugar de memória... memórias de um lugar: patrimônio imaterial de Igatu, Andaraí, BA. PASOS: Revista de Turismo y Patrimônio Cultural. Ilhas Canárias, Espanha, 2008. Disponível em: http://www.pasosonline.org/es/articulos/321lugar_de_memoria_memorias_de_um_lugar_patrimonio_imaterial_de_igatu_andara_ba. Acesso em: 23 de Nov.2018. 
CABRAL, Luiz Otávio. Revisitando as noções de espaço, lugar, paisagem e território, sob uma perspectiva geográfica. Revista de Ciências Humanas, Florianópolis, EDUFSC, v. 41, n. 1 e 2, p. 141-155, Abril e Outubro de 2007.

CARLOS, Ana Fani Alessandri. A condição espacial. $1^{\circ}$ ed. - São Paulo: Contexto, 2015.

CARLOS, Ana Fani Alessandri. O lugar no/do mundo. FFLCH, São Paulo, 2007.

Disponível em:

http://www.gesp.fflch.usp.br/sites/gesp.fflch.usp.br/files/O_lugar_no_do_mundo.pdf . Acesso em: 22 de Nov. 2018.

GASTAL, Susana de A. Lugar de memória: por uma nova aproximação teórica ao patrimônio local. In: Gastal. S. (org). Turismo, investigação e crítica. São Paulo, 2002, Contexto, p. 6981. Disponível em: https://editoracontexto.com.br/autores/susana-gastal/turismo.html . Acesso em 23 de Nov. 2018.

GOMES, Verônica Maria da Silva. "Kò SÍ EWÉ, KÒ Sí ÒRİsÀ” (SEM FOLHA, NÃo HÁ ORIXÁ): Vivências ecológicas no Ilé Àse Opó Osogunlade. 2015. 202 f. Tese (Doutorado) - Universidade de Brasilia, Facudade de Educação, Brasília, 2015.

HARVEY, David. O espaço como palavra-chave. Niterói - RJ: GEOgraphia, v. 14, n. 28, 2012. Disponível em: http://periodicos.uff.br/geographia/index. Acesso em: 22 de Nov. 2018.

LEFEBVRE, Henri. A produção do espaço. Tradução de: Doralice Barros Pereira e Sérgio Martins. $4^{\circ}$ ed. Paris: Éditions Anthropos, 2000. Título original: La production de l'espace.

MOREIRA, Erika Vanessa; HESPANHOL, Rosângela Aparecida de Medeiros. O lugar como uma construção social. Revista Formação, n 14, v. 2, p. 48-60, Presidente Prudente, 2007. Disponível em: http://www2.fct.unesp.br/pos/geo/revista/artigos/6_moreira_e_hespanhol.pdf. Acesso em: 22 de Nov. de 2018.

NORA, Pierre. Entre a memória e história: A problemática dos lugares. Trad. YaraAun Khoury. In: Projeto História, São Paulo, 1993. Disponível em: https://revistas.pucsp.br/index.php/revph/article/view/12101/8763. Acesso em: 22 de Nov.de 2018.

TUAN, Yi-Fu. Espaço e lugar: A perspectiva da Experiência. Difel. São Paulo, 1983. Disponível em: https://www.academia.edu/16998681/ESPA\%C3\%87O_E_LUGAR__A_perspectiva_da_Experiencia_-_Yi-Fu_Tuan. Acesso em: 22 de Nov.de 2018. VERGER, Pierre Fatumbi. Orixás. $6^{\circ}$ ed. Salvador: Corrupio, 2009. 